OPEN ACCESS

Edited by:

Gianni Ciofani

Italian Institute of Technology (IIT), Italy

Reviewed by:

Nanasaheb D. Thorat,

University of Limerick, Ireland

Shuwen Zeng,

Centre National de la Recherche

Scientifique (CNRS), France

*Correspondence:

Karen Pilkington

karen.pilkington@port.ac.uk

Specialty section:

This article was submitted to

Nanobiotechnology,

a section of the journal

Frontiers in Bioengineering and

Biotechnology

Received: 27 March 2020

Accepted: 20 July 2020

Published: 07 August 2020

Citation:

Bracher M, Pilkington GJ, Hanemann $\mathrm{CO}$ and Pilkington $\mathrm{K}$ (2020) A Systematic Approach to Review of in vitro Methods in Brain

Tumour Research (SATORI-BTR):

Development of a Preliminary

Checklist for Evaluating Quality

and Human Relevance.

Front. Bioeng. Biotechnol. 8:936.

doi: 10.3389/fbioe.2020.00936

\section{A Systematic Approach to Review of in vitro Methods in Brain Tumour Research (SAToRI-BTR): Development of a Preliminary Checklist for Evaluating Quality and Human Relevance}

\author{
Mike Bracher ${ }^{1}$, Geoffrey J. Pilkington ${ }^{2}$, C. Oliver Hanemann ${ }^{3}$ and Karen Pilkington ${ }^{4 *}$ \\ ${ }^{1}$ School of Health Sciences, Faculty of Environmental and Life Sciences, University of Southampton, Southampton, \\ United Kingdom, ${ }^{2}$ School of Pharmacy and Biomedical Sciences, University of Portsmouth, Portsmouth, United Kingdom, \\ ${ }^{3}$ Institute of Translational and Stratified Medicine, University of Plymouth, Plymouth, United Kingdom, ${ }^{4}$ School of Health \\ and Social Care Professions, University of Portsmouth, Portsmouth, United Kingdom
}

Background: A wide range of human in vitro methods have been developed and there is considerable interest in the potential of these studies to address questions related to clinical (human) use of drugs, and the pathobiology of tumours. This requires agreement on how to assess the strength of evidence available (i.e., quality and quantity) and the human-relevance of such studies. The SAToRI-BTR (Systematic Approach To Review of in vitro methods in Brain Tumour Research) project seeks to identify relevant appraisal criteria to aid planning and/or evaluation of brain tumour studies using in vitro methods.

Objectives: To identify criteria for evaluation of quality and human relevance of in vitro brain tumour studies; to assess the general acceptability of such criteria to senior scientists working within the field.

Methods: Stage one involved identification of potential criteria for evaluation of in vitro studies through: (1) an international survey of brain tumour researchers; (2) interviews with scientists, clinicians, regulators, and journal editors; (3) analysis of relevant reports, documents, and published studies. Through content analysis of findings, an initial list of criteria for quality appraisal of in vitro studies of brain tumours was developed. Stage two involved review of the criteria by an expert panel (Delphi process).

Results: Results of stage one indicated that methods for and quality of review of in vitro studies are highly variable, and that improved reporting standards are needed. 129 preliminary criteria were identified; duplicate and highly context-specific items were removed, resulting in 48 criteria for review by the expert (Delphi) panel. 37 criteria reached agreement, resulting in a provisional checklist for appraisal of in vitro studies in brain tumour research. 
Conclusion: Through a systematic process of collating assessment criteria and subjecting these to expert review, SAToRI-BTR has resulted in preliminary guidance for appraisal of in vitro brain tumour studies. Further development of this guidance, including investigating strategies for adaptation and dissemination across different sub-fields of brain tumour research, as well as the wider in vitro field, is planned.

Keywords: in vitro, quality appraisal, evaluation, critical appraisal, brain tumour, cancer, systematic review

\section{INTRODUCTION}

There is currently a drive to review the use of animals in research for both scientific and ethical reasons. A wide range of in vitro methods have been developed and, increasingly, there are suggestions that these can replace the use of animals in research (NC3Rs, 2020). In order for in vitro studies to be considered for replacement of in vivo (animal) studies to answer questions related to the clinical (human) use of drugs and pathobiology of tumours, there must be agreement on the strength of evidence available (i.e., the quality and quantity of studies) as well as their relevance. Judging the strength of evidence requires that all relevant research is located, each research study is assessed for quality and, if appropriate, the results of the individual research studies are combined to give an overall 'answer' and/or a clear picture of the current research on the topic in question. This process can also reveal poor research practises, unreliable reporting of research and unnecessary replication and duplication (Hartung et al., 2019). Any such practises, if left undetected, would render efforts to replace animal research less likely to gain acceptance.

Methods for assessing clinical (human) studies are welldeveloped, led by organisations such as the international Cochrane collaboration (Higgins and Green, 2011). 'Systematic reviews' of the evidence are regularly published (over 140,000 systematic reviews are listed on PubMed as of March 2020). Wellconducted systematic reviews of clinical studies are widely used as the basis for clinical decisions.

A parallel development has taken place for animal studies. CAMARADES (Collaborative Approach to Meta-Analysis and Review of Animal Data from Experimental Studies) is an initiative to improve the design, conduct, analysis and reporting of animal experiments (CAMARADES, 2020). By means of 'precise and robust' overviews of existing data through systematic review and meta-analysis, CAMARADES aims to clearly demonstrate where further experiments are necessary, avoiding unnecessary replication. The CAMARADES initiative has generated interest and collaborative efforts on a global scale with five national coordinating centres. This is seen as crucial in efforts to reduce animal experimentation.

Reduction strategies, however, constitute only one of the Three Rs (Refinement, Reduction, and Replacement) - the underlying principles of ethical and humane use of animals in research (NC3Rs, 2020). The third principle, replacement, as described above, requires that a desired scientific goal is achieved by approaches other than those involving live animals, such as through use of in vitro studies. As with the CAMARADES initiative 'precise and robust' overviews of existing research are essential to provide a clear picture of the research (Nuffield Council on BioEthics, 2005). However, as Hartung et al. observe, '[while] [m] any areas have developed reporting standards and checklists to support the adequate reporting of scientific efforts. . . in vitro research still has no generally accepted criteria... [and] such a culture may undermine trust in the reproducibility of animal-free methods' (Hartung et al., 2019). Thus, there is a need to evaluate and develop current practises for assessing quantity and quality of in vitro studies of brain tumours and their potential to replace in vivo (animal) studies.

As Hartung et al. (2019) indicate, issues in reporting are not restricted to specific areas of interest (such as brain tumours) but encompass the broad field of in vitro research. Searches on a major scientific database (PubMed) reveal that while reviews have been published and described as systematic reviews of in vitro studies, many fail to apply key principles and processes expected of such studies. For example, one publication reported the databases searched and inclusion criteria, but not whether any quality criteria were applied (Laaksonen et al., 2010). A second 'systematic review' assessed each study based on two criteria defined by the authors (type of publication and whether there was a 'comparable baseline'), and reported the lack of generally accepted evaluation criteria for in vitro studies (Xiao et al., 2011). A third review revised an existing tool for assessing diagnostic studies using four selected criteria (Deng et al., 2016). Few details are reported on exactly how these criteria were applied. Another study attempted to provide an overview of guidance systems with evaluation criteria for in vitro studies on chemical toxicity (Lynch et al., 2016). The criteria compared were from four sources [Animal Research: Reporting of in vivo Experiments (ARRIVE) (Kilkenny et al., 2010), Klimisch et al. (1997) on evaluating the quality of toxicological data; OECD Guidance Document on the Validation and International Acceptance of New or Updated Test Methods for Hazard Assessment (OECD, 2005); Toxicological Data Reliability Assessment Tool (ToxRTool) (Schneider et al., 2009)]. The criteria include reporting requirements, categories to be scored and items to be assessed. Few criteria were common to all 4 sources. Furthermore, while criteria for assessment of the quality of studies is crucial for unbiased, reliable reviews of the research literature, assessment of relevance of the technique or method employed is also a key element.

Both development of reporting standards for in vitro research (Hartung et al., 2019) as well as adoption of existing guidance (Pamies et al., 2017; Hartung et al., 2019) remain issues across the broad field of in vitro research. This study specifically focuses on brain tumour research, with the intention of providing a model for other areas. We have selected brain tumour as a particular area for study because although many brain tumours can be 
cultured in the laboratory with relative ease, there are specific challenges in gaining accurate biological information from cells which have been removed from such a complex multicellular organ as the brain. Not only are brain tumour cells reliant on the non-neoplastic cells such as glial and immune cells for their resistance to therapeutics, but they are also reliant on the very special vasculature of the brain and indeed the blood brain barrier which protects against toxins but inhibits delivery of therapeutics. Provision of sophisticated, complex 3D models of the brain and its vasculature, including organoids, induced pluripotent stem cells and blood brain barrier elements for pre-clinical drug delivery and sensitivity are perhaps the most complex forms of all human tissue in vitro systems and, if we can produce best practise criteria for this area we can roll this out for many other areas of research.

The overall aim of the SAToRI-BTR project is to explore how in vitro studies could be presented as a body of knowledge in the form of a rigorous and comprehensive systematic review, to assess the potential for replacement of animal studies for answering specific questions in brain tumour research. SAToRIBTR seeks to address these challenges by assessing reviews of existing studies (published systematic reviews) and identifying areas for potential improvement and investigating current practise and views on how in vitro studies of brain tumours should be assessed, leading to agreed criteria.

The aim of the study reported in this paper was to explore potential methods for the systematic identification, and assessment of quality and appropriate use of in vitro studies through a process involving identification of existing criteria which were subject to expert review in order to develop draft criteria.

\section{MATERIALS AND METHODS}

The project to develop a set of appropriate criteria for assessment of quality and human relevance in in vitro studies of brain tumours was carried out in two stages. The first stage involved identification for potentially relevant criteria through collection and analysis of appropriate data (stage one), and the second stage focused on obtaining agreement on identified criteria by an expert panel by means of a Delphi process (stage two see Figure 1).

The overall process followed that developed by the EQUATOR (Enhancing the QUAlity and Transparency Of health Research) Network which was used for development and agreement on reporting guidelines for systematic reviews (PRISMA: Preferred Reporting Items for Systematic Reviews and Meta-Analyses) (Moher et al., 2009). This required documenting the need for a set of guidelines by reviewing previously published systematic reviews and the methods and reporting of these, reviewing existing literature to identify potential criteria. It also draws on the methods used to establish CONSORT (Consolidated Standards of Reporting Trials) (Moher, 1998) and the Cochrane collaboration's tool for assessing risk of bias in trials (Higgins et al., 2011).

Therefore, at stage two, these criteria were put to a panel (Delphi) of senior researchers, who were asked to rate their

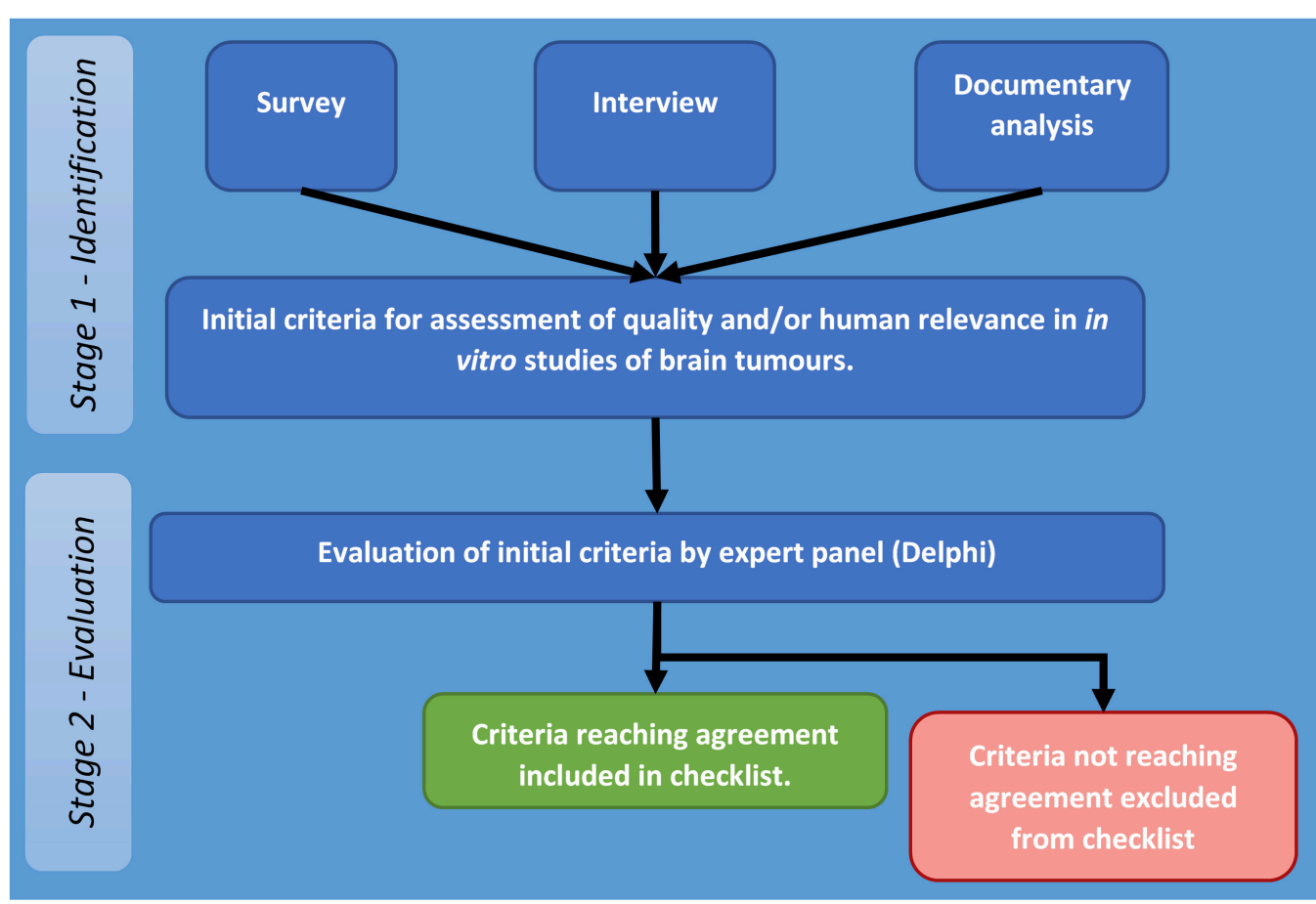

FIGURE 1 | Flow diagram of stages and procedures in identification and evaluation of criteria for assessment of quality and/or human relevance in in vitro studies of brain tumours. 
appropriateness for assessing quality and human relevance in in vitro studies of brain tumours. Criteria reaching agreement form the basis of the checklist reported in this study.

\section{Summary of the Overall Approach}

- Pre-stage (documenting the need for a set of criteria/guidelines)

- Search for and review of previously published systematic reviews in the field of in vitro cancer research.

- Examination of all papers described as systematic reviews of in vitro cancer studies to assess the quality/relevance assessment tools that had been used.

- Stage one (identifying potential criteria)

- Survey of senior brain tumour researchers to obtain a list of all in vitro techniques that are used in brain tumour research, suggested criteria, areas of agreement, relevant guidance, or quality-related initiatives.

- Interviews with a pre-defined sample of leading and emerging researchers, journal editors, senior clinicians, funding body, and regulatory committee representatives to elicit views on how quality and relevance should be assessed.

- Examination of peer review guidelines from major journals in the field for potential quality criteria for in vitro studies.

- Identification and analysis of all documents presenting potential quality criteria.

- Collation of the findings of the documentary analysis, and the survey and interview data.

- Development of a draft set of criteria for assessing in vitro studies based on the findings of the above.

\section{- Stage two (gaining agreement on criteria for the guidelines)}

- Establishment of a panel of experts in the field of brain tumour in vitro research.

- Use of the Delphi method to obtain agreement on key criteria to be used for assessing in vitro studies.

\section{Pre-stage}

Searches were carried out using five databases for systematic reviews of in vitro cancer studies. All reviews that were described as a 'systematic review' and which focused solely on in vitro studies in any form of cancer were selected and the full-text checked for relevance. Those that met the inclusion criteria were selected and the data extracted on aspects including the focus and methods used. The full details of this review are to be published as a separate paper.

\section{Stage One \\ Quality Criteria in Previously Published Systematic Reviews}

All relevant systematic reviews identified in the pre-stage review were selected and the full-text checked for mention of, or reference to, quality criteria, a checklist for quality, or guidance used to judge quality and/or human relevance of included studies.

\section{Survey of Brain Tumour Researchers}

An online survey was conducted to investigate current areas of research interest/focus related to in vitro research; in vitro models and study methods used within these areas; methods for assessing quality and relevance in these areas and knowledge of any published guidelines, checklists or quality initiatives.

Questions were developed by the authors with a draft version piloted followed by further revisions before the survey was finalised. The survey was completed online, using the University of Portsmouth's online survey platform provider (Online Surveys.ac.uk) and was completed anonymously. A copy of the full set of questions in the questionnaire is available from the authors on request.

Potential participants were identified from conference abstracts for oral and poster presentations from international conferences and scientific meetings. See Table $\mathbf{1}$ for a list of sources used to identify potential participants. Once identified, further information was sought on participants from publicly available sources such as departmental, ResearchGate, and Google Scholar web pages. Those meeting inclusion criteria and for whom contact details could be found were approached for participation. Inclusion criteria were:

- Scientist working on studies of brain tumours using in vitro methods.

- Evidence of further publication history within brain tumour field using in vitro methods beyond conference abstract through which initially identified.

Potential participants were approached through published email addresses obtained from conference abstracts, departmental or professional web pages, or other publications. Design of invitations was informed by Fan and Yan's (2010) recommendations drawn from a systematic review of factors affecting response rates in web surveys. Email invitations used a personalised salutation, identified survey tasks and salience, described how recipients were identified as potential participants, provided estimation of the time to finish the survey and gave contact details for further questions and assistance (Fan and Yan, 2010).

While no specific methodological guidance was available for conducting surveys of pre-clinical scientists, this target population was hypothesised to share many of the characteristics likely to affect participation which have been identified in previous studies with senior managers in other kinds of organisation. These include increased sensitivity to personalised responses, declining time capacity for participation due to increasing pressures from their core roles (Cycyota and Harrison, 2006), and an increasingly saturated information environment (e.g., email and social media) in which there are high levels of competition for feedback (and thus participant time). The potential vulnerability of the survey to low response in spite of efforts to implement best practise guidance formed part of the rationale for using multiple sources of data (i.e., survey, interviews, and documentary analysis) to inform the Delphi process, in order to make the project overall more resilient to the limitations of any single data collection stream. 
TABLE 1 | Identification of potential participants by source.

\begin{tabular}{|c|c|c|c|c|}
\hline Meeting/source & $\begin{array}{l}\text { Abstracts screened } \\
\text { (n) }\end{array}$ & $\begin{array}{l}\text { Abstracts indicating } \\
\text { in vitro research }(n)\end{array}$ & $\begin{array}{l}\text { Potential participants } \\
\text { excluded* }(n)\end{array}$ & $\begin{array}{l}\text { Potential participants } \\
\text { approached }(n)\end{array}$ \\
\hline $\begin{array}{l}\text { World Federation of Neuro-oncology Societies } \\
\text { (WFNOS) } 2017 \text { Meeting (WFNOS, 2017a,b) }\end{array}$ & 481 & 165 & 65 & 100 \\
\hline $\begin{array}{l}\text { Society for Neuro-oncology (SNO) } 2017 \text { Annual } \\
\text { Meeting (SNO, 2017a,b) }\end{array}$ & 1248 & 224 & 56 & 168 \\
\hline $\begin{array}{l}\text { European Association of Neuro-Oncology 13th } \\
\text { Meeting (2018) (EANO, 2018) }\end{array}$ & 446 & 157 & 61 & 96 \\
\hline $\begin{array}{l}\text { British Neuro-Oncology Society (BNOS) } 2017 \\
\text { Meeting (BNOS, 2018) }\end{array}$ & 119 & 14 & 3 & 11 \\
\hline $\begin{array}{l}\text { Asian Society for Neuro-Oncology (ASNO) 14th } \\
\text { Meeting (2017) (ASNO, 2017) }\end{array}$ & 240 & 52 & 27 & 25 \\
\hline $\begin{array}{l}\text { Sub-Saharan Africa Neuro-Oncology } \\
\text { Collaborative (S-SANOC) } 2017 \text { Planning } \\
\text { Meeting (S-SANOC, 2017) }\end{array}$ & 25 & 17 & 14 & 3 \\
\hline $\begin{array}{l}\text { Additional (potential participants identified } \\
\text { through other sources, e.g., team members or } \\
\text { other neuro-oncologists) }\end{array}$ & & & & 33 \\
\hline Totals & 2559 & 629 & 193 & 436 \\
\hline
\end{tabular}

${ }^{*}$ Not in vitro specialist OR not neuro-oncology specialist OR no contact information available.

Interviews With Key Individuals From the in vitro Field Semi-structured interviews used widely to explore in-depth contextual factors affecting practise change (e.g., regulatory, funding, and variations in clinical or scientific practise) (Carlsen et al., 2007; Gardner and Webster, 2016; Colquhoun et al., 2017). A purposive sampling frame was constructed to reflect the different roles relevant to in vitro research. These included scientists, clinicians, regulators, and journal editors involved with studies using in vitro methods (including those working in fields other than brain tumour research, e.g., other neurological disease, other forms of cancer). Participants were identified through publications, professional and regulatory activities, and via the project team. An interview guide was developed and piloted with focus on the potential helpfulness and scope of set criteria, likely extent of agreement on assessment of in vitro research and the specific challenges in getting guidelines widely accepted.

The interviews aimed to explore:

- Professional opinion and practise in evaluation of quality and human relevance of in vitro models for brain tumour research, and identify points of agreement and disagreement.

- Current practises, opinions, and resources for identifying in vitro studies for review in brain tumour research.

- Factors that may promote or inhibit introduction of new practises for assessment of quality and human relevance in brain tumour research.

Interviews were carried out by phone after confirming consent with the participant. All interviews were guided by a set of core questions developed through pilot interviews, with follow up questions and exploration taking place where appropriate (and depending on the expertise and interest of respective participants). The semi-structured nature of interviews therefore meant that there was some variation in the length of interviews, number of questions asked, and in development of the interview schedule as the study progressed. Interviews were recorded and transcribed for directed content analysis in Nvivo (v12) Computer-assisted Qualitative Data Analysis Software (CAQDAS) (QSR International, 2018). Nvivo allows users to attach labels (or 'codes') to text, audio, video or image data, and facilitates data management through which directed content analysis can be conducted by a competent user. This involved reading across interview transcripts to identify responses relevant to the above aims (Corbin and Strauss, 2014).

\section{Exploration of Author and Peer-Reviewer Guidance Provided by Journals}

A set of relevant journals was identified using the following techniques:

- The 50 journals appearing most frequently in the results of searching the Medline database using the index term "In vitro Techniquest".

- The 50 journals appearing most frequently using the search "In vitro Techniques+" AND "Neoplasmst" (both as index terms).

- The top 20 ranked journals from both the 'Oncology' and 'Cancer Research' categories of the Scimago Scientific Journal Rankings.

Resulting journals were combined into a single list, which after duplicate removal resulted in a set of unique journals for assessment of author and peer-review guidance. Assessment was conducted through manual exploration of journal websites, to identify publicly available information on author and peer-review guidance pertaining to quality assessment of in vitro methods. 


\section{Identification of Relevant Documents}

Relevant documents including guidelines on the conduct and reporting of in vitro research, published standards were identified through the following methods:

- Previous review of published systematic reviews.

- 101 journal websites searched for general guidance on in vitro-relevant study reporting, and quality appraisal for specific techniques.

- Feedback from survey and interview responses.

- Searches of reporting guidance databases [e.g., US National Institutes of Health (NIH), EQUATOR Network FAIRSharing.org (2020)], the PubMed database and a commercial social networking site for scientists and researchers (ResearchGate).

All documents were loaded into NVivo software for directed content analysis.

\section{Analysis}

Survey

Descriptive statistical analysis was performed on quantitative data, and responses to free-text questions were analysed using a content analysis approach, where data area grouped into categories (e.g., cell line authentication and replication) for reporting (Krippendorff, 2018). For this aspect of the SAToRIBTR project, data on quality and relevance criteria that are used in practise (e.g., when peer reviewing) and any quality initiatives or guidelines were extracted.

\section{Interviews}

Full interview transcripts were uploaded to Nvivo and directed content analysis of data was performed using Nvivo. Through this process, any data on quality and relevance criteria used in practise, and any quality initiatives or guidelines were identified and collated in order to inform stage two.

\section{Documents}

Directed content analysis was also performed on documents using Nvivo software.

\section{Collation and Compilation of List of Proposed Criteria}

A full list of all criteria was generated and a comparison of the criteria from documentary analysis compared with those from the survey and interviews. Any additional criteria generated from the latter were added to the list. The initial list was then further reviewed for duplicate criteria (i.e., those assessing the same or similar aspects but which were phrased in different terms which could be merged), ensuring that those criteria highlighted in several sources were retained and those that related only to a specialised technique were removed. The outcome of stage one was identification of a range of criteria for assessment of quality and/or human relevance in in vitro studies of brain tumours, which were organised in a taxonomy by area of focus.

\section{Stage Two}

Having identified potential assessment criteria for in vitro studies of brain tumours at stage one through international survey, telephone interview, and documentary analysis, stage two involved evaluation of appropriateness of these criteria for assessment of brain tumour studies by a panel of senior scientists. The expert agreement panel (or 'Delphi') process has been used extensively in clinical and health services research to develop reporting guidance and quality assessment criteria for a range of scientific and clinical applications (Fitch et al., 2001; Boulkedid et al., 2011). Delphi allows participants to rate criteria anonymously (i.e., without knowledge of the composition of the panel, or identities of members), and to provide written feedback on them. The process occurs across multiple rounds, between which comments from all participants are also circulated so each participant is aware of the range of opinions and the reasons underlying these. Criteria reaching agreement are removed, additional criteria may be added, or existing criteria amended if they have not reached agreement (e.g., in response to suggestions from the panel). The process is anonymous and usually three rounds of the survey are sufficient to achieve reasonable agreement (Fitch et al., 2001; Hsu Chia and Brian, 2007; Boulkedid et al., 2011).

Delphi has been used both as a standalone technique to reach agreement on reporting and assessment criteria, and also as a sorting procedure to identify criteria of ongoing controversy requiring further discussion by a subsequent panel of experts (Boulkedid et al., 2011). As the aim of SAToRI-BTR is to identify agreed criteria, this method was assessed as appropriate for either outcome in terms of wider development of the project in the future.

\section{Identification and Approach of Participants}

Professors, heads of laboratories, and principal investigators who had been previously identified at either the survey or interview stages were invited to participate via personalised email and physical letter as described at the survey stage. Following indications of willingness to participate, participants were sent a link to complete the online consent form, after which they were invited to participate in the first round of the Delphi panel.

\section{Development of Initial Criteria}

Criteria identified at stage one were evaluated by expert members of the SAToRI-BTR Team and results grouped into categories for assessment by the panel.

\section{Rating and Progression Between Rounds}

Participants rated criteria on an 9-point scale: 1 (not at all relevant) to 9 (essential) to assessment of a brain tumour study'. They were invited to leave qualitative comments (e.g., on context of application, clarity of criterion etc.) (Boulkedid et al., 2011) and to suggest additional criteria for each category (see Figure 2).

Criteria were judged to have reached agreement according to the RAND/UCLA agreement criteria (Fitch et al., 2001, p. 58). Criteria reaching agreement were removed between rounds, additional criteria added (if suggested by participants), and existing criteria not reaching agreement changed in line with participant feedback or (in its absence) passed to the next round unchanged. 


\section{Compliance with Good Laboratory Practice (GLP)}

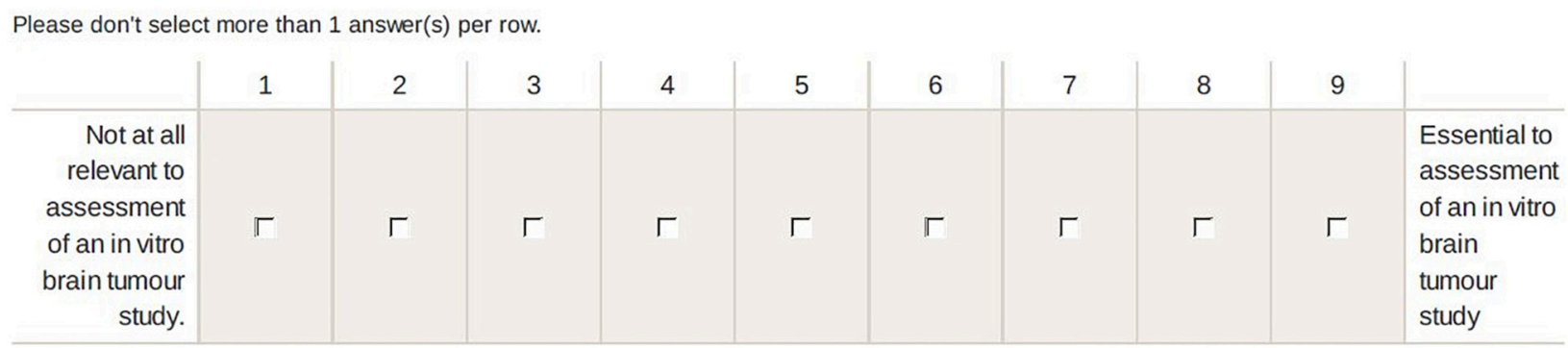

Do you have any comments on the above criterion?

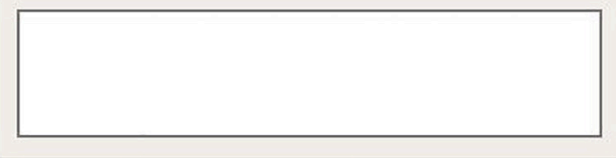

FIGURE 2 | Example of Delphi rating scale and written feedback facility.

The final outcome of stage two was a set of criteria around which agreement was obtained on their importance for the assessment of quality and relevance.

\section{Ethical Approval}

Ethical approval for the survey, interviews, and Delphi processes was granted by the University of Portsmouth Faculty of Science Ethics Committee, reference number SFEC 2018-073 (original application plus amendments).

\section{RESULTS}

\section{Pre-stage (Review of Published Systematic Reviews of in vitro Studies)}

The review of published systematic reviews of in vitro studies indicated that few were available. Not all those described as systematic applied systematic approaches to the literature. Analysis of the methods used in the reviews confirmed that there was not a widely used set of criteria for assessing quality and/or relevance of in vitro studies. Those that did conduct a systematic appraisal of the included studies, adapted a wide range of existing appraisal checklists. A lack of agreed criteria specific to in vitro studies was highlighted.

\section{Stage One}

\section{Survey of in vitro Brain Tumour Researchers}

A total of 436 researchers were contacted and invited to complete the online questionnaire (see Figure 3). Of those invited, $7.8 \%$ (34 participants) completed the survey. Sixteen were from the United States, 12 from Europe, five from the United Kingdom and one from South America. A total of 10 different countries were represented. $30(88 \%)$ participants identified as either 'Professor/Department Head' or 'Research
Team Lead.' Mean years' experience in brain tumour research $17.6(S D=10.1$, range $=3-40) .28$ participants $(85 \%)$ also use in vivo techniques. The participants recommended a range of potential quality criteria.

\section{Interviews}

Thirty-four potential participants approached via email and letter, of which 13 participants completed the interview (see Figure 4). The participants included/represented: professors/head of laboratories, consultant clinicians, industry, those leading quality and human relevance initiatives, regulators and journal editors. Telephone interviews totaled $414 \mathrm{~min}$, with an average length of $34.46 \mathrm{~min}$ (range $=17-58 \mathrm{~min}$, $S D=12.92 \mathrm{~min}$ ).

Responses indicated:

- Methods for reviews of in vitro studies are highly variable;

- Quality of reviews of in vitro studies varies;

- Need for improved reporting standards.

Participants described a number of relevant quality assurance documents and reporting standards. Views were also expressed on the involvement of clinicians and regulators in development and barriers to adoption of any suggested guidelines or quality initiatives. More detailed results are to be reported in subsequent published works.

\section{Exploration of Author and Peer-Reviewer Guidance Provided by Journals}

Of the 101 unique journal titles identified, 6 journals had been discontinued or renamed, 2 were book series and 1 journal was inaccessible. Identifying and including the replacement titles for the renamed journals resulted in a total of 96 journals currently in print and accessible which could be assessed. Fiftyeight (60\%) journals did provide some guidance specific to or 


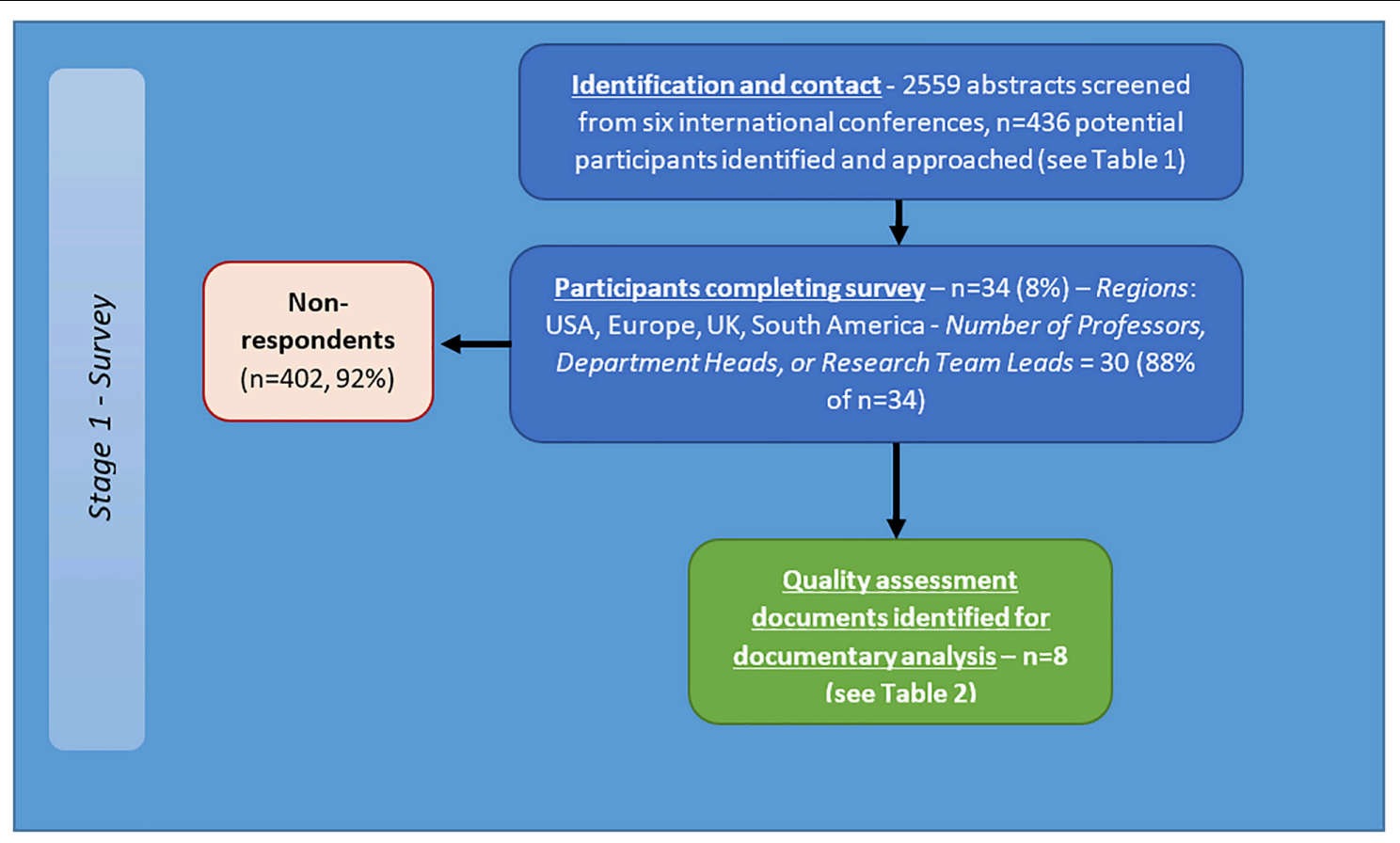

FIGURE 3 | Flow diagram of recruitment and results for international survey of brain tumour researchers.

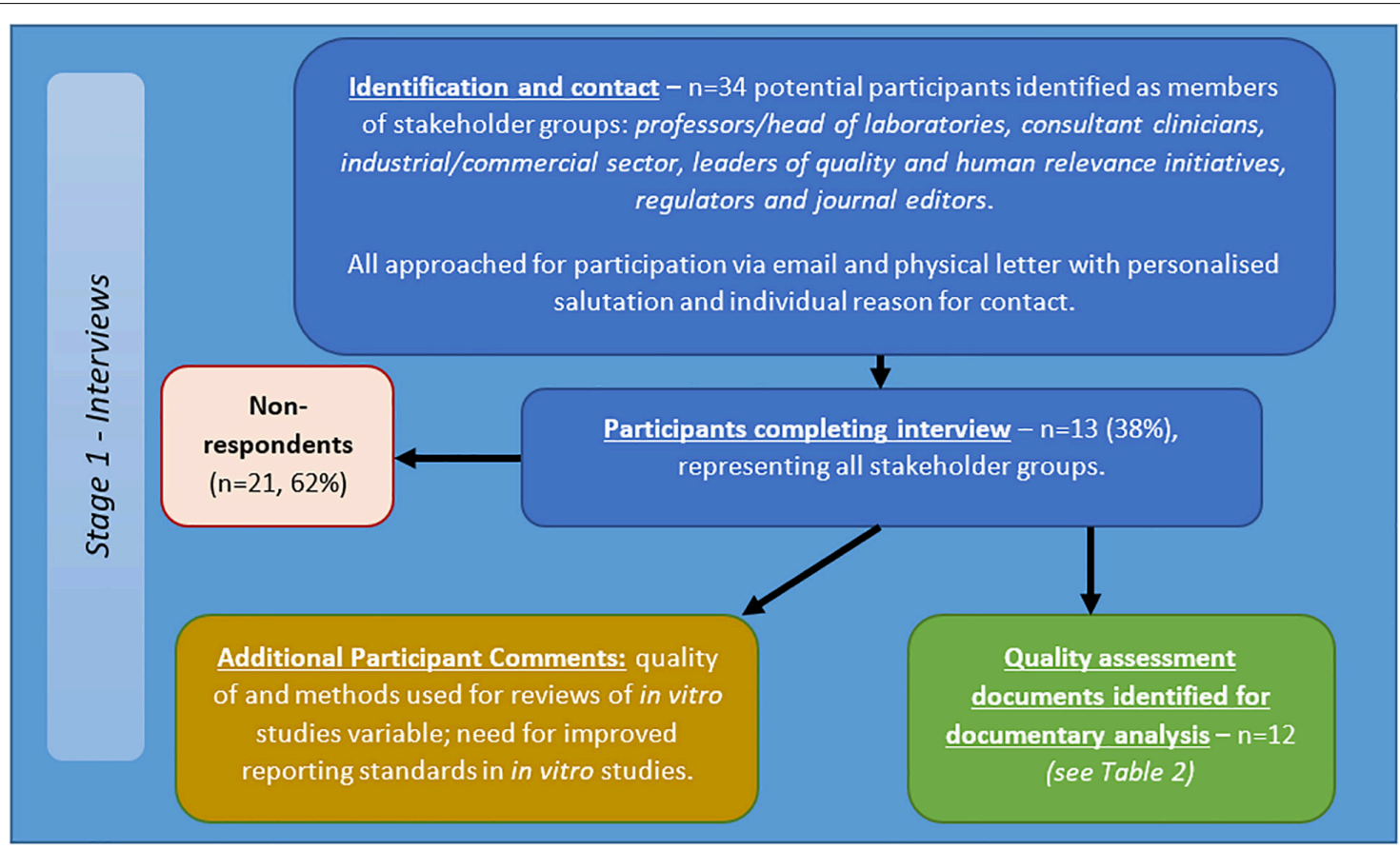

FIGURE 4 | Flow diagram of recruitment and results for semi-structured interviews with stakeholders in in vitro studies of brain tumours

relevant to in vitro techniques. Thirty-eight (40\%) did not appear to provide any guidance accessible on the website that was specific to in vitro research. Established guidelines were reported by 25 journals (26\%). These guidelines included those on specific techniques which could be, but are not exclusively, applied in in vitro research, such as MIAME (Minimum Information About a Microarray Experiment) and STRENDA (Standards for Reporting Enzymology Data). Generic guidelines were also cited such as the National Institute for Health (NIH) Principles and Guidelines for Reporting Preclinical Research. Cell line 
TABLE 2 | Quality assessment documents identified for analysis including sources.

Documents

Survey

Interviews

Searches of journal criteria

and assessment

databases

Tools for methodological quality and risk of bias (Al Saadi et al., 2016)

Cell culture techniques [edited collection] (Aschner et al., 2011)

Minimum information about a microarray experiment (MIAME) - toward standards for microarray data (Brazma

et al., 2001)

STAR methods guide (CELL Press, 2020)

Six checklists relating to in vitro models for different organs/systems [COMMERCIAL ENTERPRISE] ${ }^{*}$

Quality of reporting in systematic reviews - meta-analyses of in vitro studies - a systematic review protocol (Elshafay

et al., 2019)

Good cell culture practises and in vitro toxicology (Eskes et al., 2017)

EU-NETVAL meeting 10-11th October 2016 (EU-NETVAL, 2016)

EU-NETVAL meeting 26th-27th November 2015 (EU-NETVAL, 2015)

GOOD IN VITRO METHOD PRACTISES (GIVIMP) (OECD, 2018)

EURL ECVAM workshop - inaugural meeting of EU-NETVAL members - 26-27 June 2014 (EURL ECVAM, 2014)

Guidelines for the use of cell lines in biomedical research (Geraghty et al., 2014)

Perspectives on in vitro to in vivo extrapolations (Hartung, 2018)

Hartung et al. (2002) good cell culture practise ECVAM good cell culture practise task force report 1 (Hartung et al.,

2002)

Definitions relating to cell line authentication (ICLAC, 2019b)

Cell line checklist for manuscripts and grant applications (ICLAC, 2019a)

Better reporting for better research: a checklist for reproducibility (Kenall et al., 2015)

UKCCCR guidelines for the use of cell lines in cancer research (UKCCCR, 2000)

Reporting recommendations for tumour marker prognostic studies (REMARK) (McShane et al., 2005; Altman et al., 2012)

Enhancing reproducibility through rigour and transparency (NOT-OD-15-103) (NIH-OER, 2015)

Guidelines for research involving recombinant or synthetic nucleic acid molecules $(\mathrm{NIH}, 2019)$

Principles and guidelines for reporting preclinical research $(\mathrm{NIH}, 2017)$

Advisory document of the working group on good laboratory practise the application of the principles of GLP to

in vitro studies (OECD, 2004)

Good cell culture practise for stem cells and stem-cell-derived models (Pamies et al., 2017)

Extending a risk-of-bias approach to address in vitro studies - a systematic review protocol (Rooney, 2015)

In vitro acute and developmental neurotoxicity screening - an overview of cellular platforms and high-throughput

technical possibilities (Schmidt et al., 2017)

Promoting coherent minimum reporting guidelines for biological and biomedical investigations - the MIBBI project

(Taylor et al., 2008)

*Documents marked [COMMERCIAL ENTERPRISE] were provided on condition of confidentiality of content.

authentication was referred to by 22 journals and related guidance that was cited included the UKCCCR Guidelines for the Use of Cell Lines in Cancer Research. A full list of the guidance that was located through review of the journal websites is included in Table 2.

For all journals still in publication and with an impact factor for $2018(n=95)$, the median impact factor (IF) was 4.9 (range $=0.6-223.7, \mathrm{IQR}=5.6)$. Of these: for journals citing established criteria $(n=25)$ the median was 5.2 (range $=1.9-$ $59.1, \mathrm{IQR}=3.5)$; for journals giving general guidance $(n=48)$ the median was 4.9 (range $=1.9-41.1, \mathrm{IQR}=3.5$ ); while for journals giving no specific guidance $(n=37)$ the median was 4.5 (range $=0.6-223.7, \mathrm{IQR}=6.7$ ).

The analysis of author and peer-review guidance provided further evidence to support the observation of a lack of common, comprehensive, quality assessment criteria for in vitro studies, by showing significant variation in the quantity and types of guidance provided by journals.

\section{Documentary Analysis}

A total of 32 documents were identified from the above sources (see Table 2). Criteria identified from analysis of these documents are reported below as part of the summary of all criteria identified from stage one (see Figure 5).

\section{Stage Two \\ Compilation of Preliminary Criteria}

Following completion of the survey, interview, and documentary analysis stages, potential criteria were collated using Nvivo software, through which a long list of 129 preliminary items were identified (see Figure 6). Duplicate and highly context 


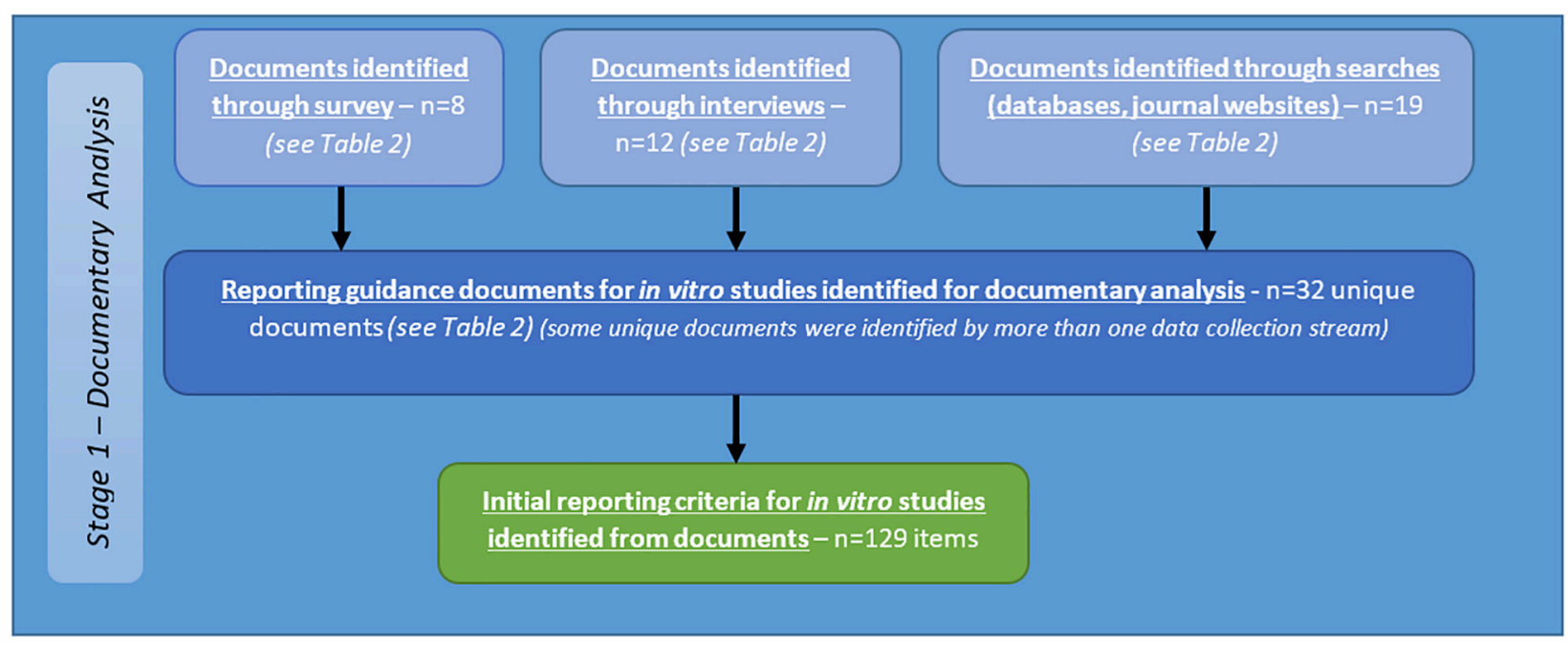

FIGURE 5 | Flow diagram describing sources of identification of reporting guidance documents, and initial criteria for reporting of in vitro studies of brain tumours resulting from documentary analysis.

specific items were removed. Forty-one criteria were selected for assessment by expert panel (Delphi) (see Table 3).

\section{Expert Panel}

Of the 38 professors, heads of laboratories, and principal investigators invited to participate by personalised email and letter, 22 agreed to participate initially. 19 participants completed round one and 18 completed round two (see Figure 6). For a comparison of those participating in the expert panel compared with those taking part in the survey and interviews, see Table 4.

\section{Delphi Assessment}

Of the initial 41 criteria, agreement was achieved in round one on 28 with no agreement on 13. Seven further criteria were suggested.

For round two, based on feedback from participants, four of the 13 criteria were merged with existing criteria, nine were represented to Delphi group (with or without rephrasing) and the seven new criteria identified by participants were also presented to the panel. Thus, a total of 16 criteria were assessed in round two and a total of 48 criteria across the two rounds.

In round two agreement was achieved on nine (including three new criteria). No agreement was apparent on seven criteria (including four new criteria). Although the level of agreement across the two rounds of Delphi completed was high, for the remaining seven criteria, the level of agreement, even when criteria were rephrased reduced and the feedback from participants indicated that achieving agreement on these was unlikely to be feasible.

The large amount of qualitative data to analyse (comments, explanations etc.) collected should further inform the application of the criteria in practise. Further specification of criteria needs discussion and, thus, it was decided that the next stage would require an in-person meeting and discussion. A summary of the process is shown in Table 4, and in Figure 6.

\section{DISCUSSION}

This study represents a first attempt to use a systematic approach to generating a set of criteria for assessing the quality and relevance of in vitro brain tumour research studies. In designing the process, the aim was to combine a systematic analysis of existing guidance and practise with the implicit views of those with expertise in in vitro brain tumour research. By attempting to engage those involved in research in this field at an early stage and throughout the process, it was anticipated that the uptake of any resulting guidance would be optimised. It was also anticipated that focusing the study in a specific area (brain tumour research) would also increase the relevance and hence engagement with the process.

There have been a number of initiatives aimed at improving and standardising the quality and reporting of in vitro research, some of which are ongoing (Eskes et al., 2017; Pamies et al., 2017; OECD, 2018; Hartung et al., 2019). Full and transparent reporting is of importance as it enables the evaluation and reproduction by other researchers and thus optimises the resources that have been expended. While various initiatives have been undertaken, adoption by researchers working in the field has been low (Pamies et al., 2017). The participants taking part in the survey and interviews conducted in this study were aware of some of these initiatives but there was not universal or consistent reference to any particular set of guidance.

The intention of screening a large number of abstracts from a series of relevant recent conferences was to ensure that a large number of researchers were involved in the survey (and thus the guideline production process). Over 2,500 abstracts were screened resulting in over 400 individual senior researchers being identified but the response rate was extremely low. There may be several explanations for this: lack of perceived relevance or concern about the ultimate aim of any guidance 


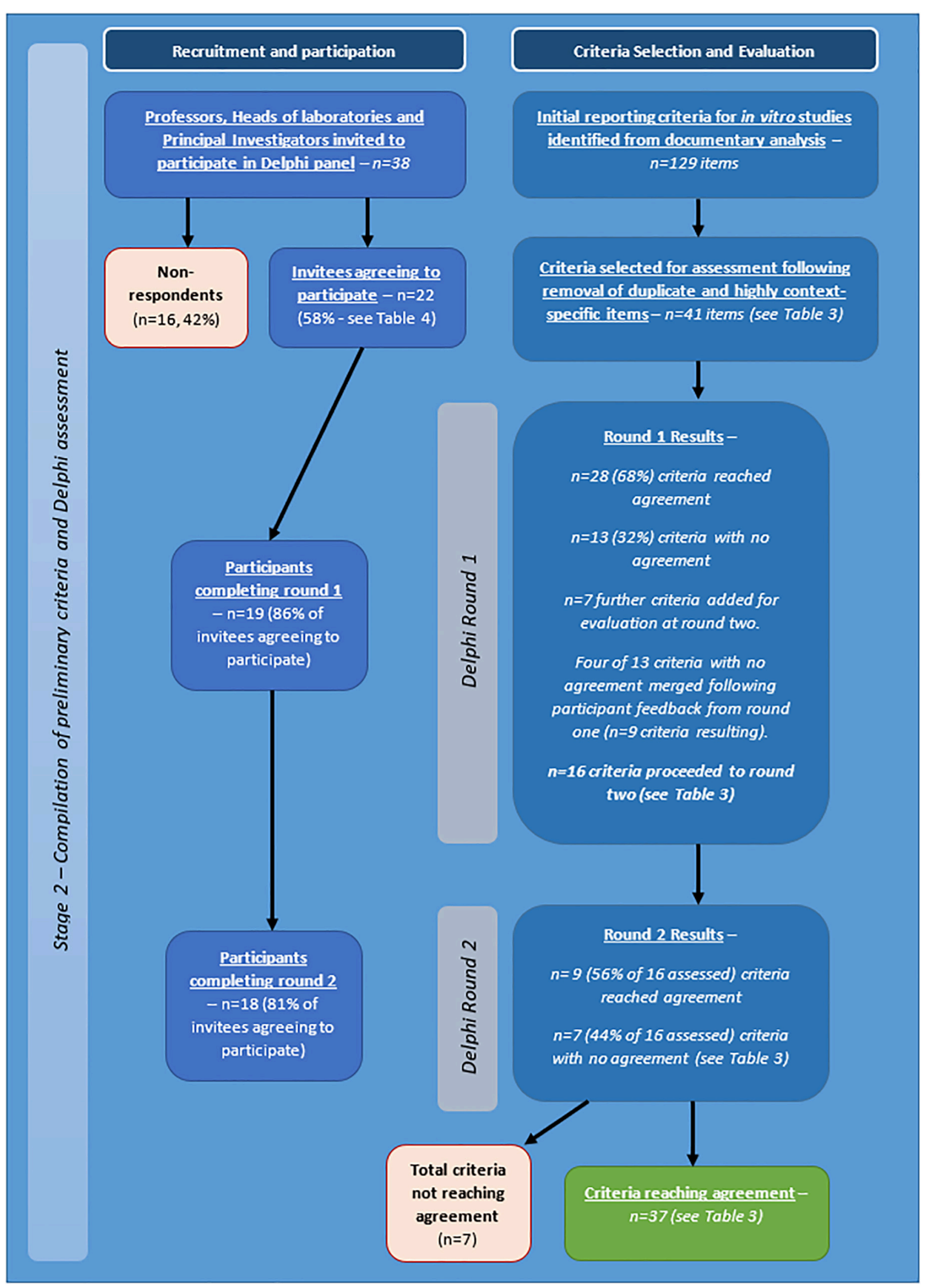

FIGURE 6 | Flow diagram describing Delphi process and outcomes. 
TABLE 3 | Summary of Delphi process (italics: no agreement).

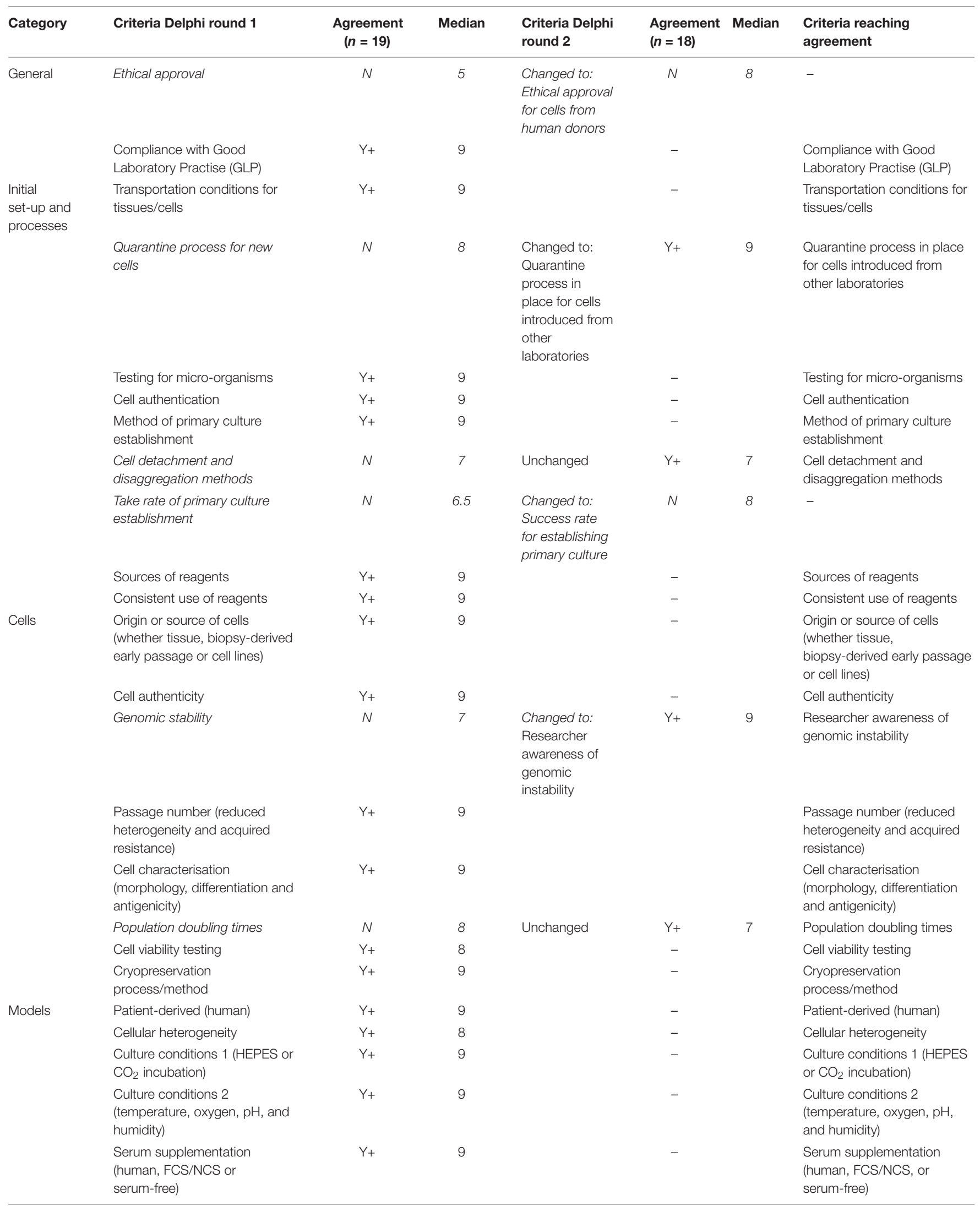


TABLE 3 | Continued

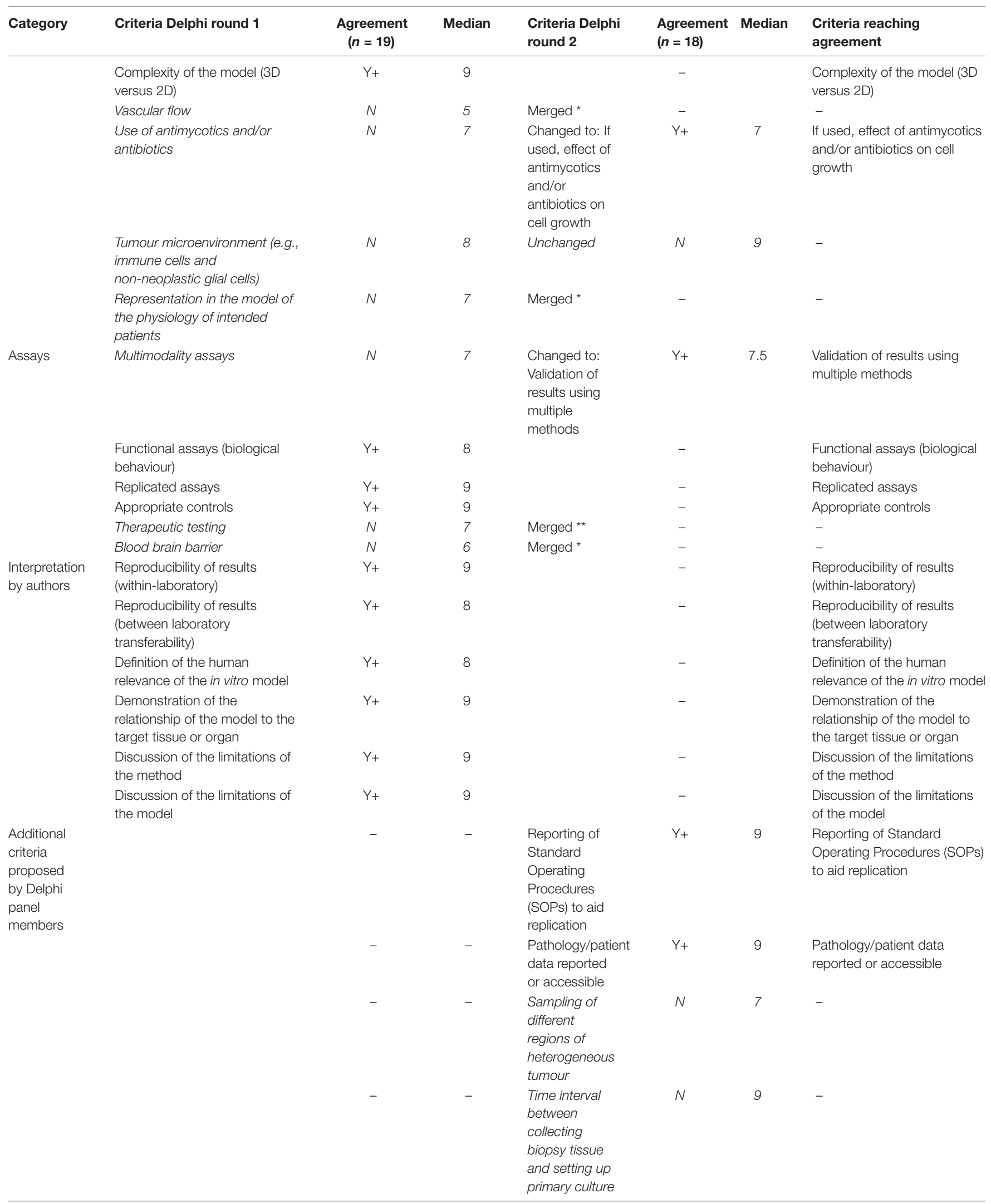


TABLE 3 | Continued

\begin{tabular}{|c|c|c|c|c|c|c|c|}
\hline Category & Criteria Delphi round 1 & $\begin{array}{l}\text { Agreement } \\
\quad(n=19)\end{array}$ & Median & $\begin{array}{l}\text { Criteria Delphi } \\
\text { round } 2\end{array}$ & $\begin{array}{l}\text { Agreement } \\
(n=18)\end{array}$ & Median & $\begin{array}{l}\text { Criteria reaching } \\
\text { agreement }\end{array}$ \\
\hline & & - & - & $\begin{array}{l}\text { Substrate on } \\
\text { which cells are } \\
\text { cultured }\end{array}$ & $Y_{+}$ & 8.5 & $\begin{array}{l}\text { Substrate on which cells are } \\
\text { cultured }\end{array}$ \\
\hline & & - & - & $\begin{array}{l}\text { Assessment of } \\
\text { imaging } \\
\text { method used }\end{array}$ & $N$ & 7 & - \\
\hline & & - & - & $\begin{array}{l}\text { Appropriate } \\
\text { use of } \\
\text { bioinformatics } \\
\text { and/or } \\
\text { mathematical } \\
\text { modelling }\end{array}$ & $N$ & 7 & - \\
\hline
\end{tabular}

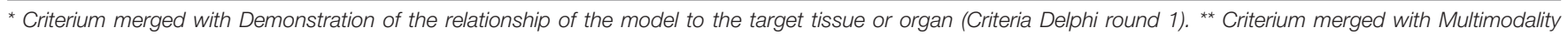
assays (Criteria Delphi round 1).

TABLE 4 | Comparison of participants in survey, interviews and Delphi.

\begin{tabular}{|c|c|c|c|c|c|}
\hline \multirow[t]{2}{*}{ Country } & \multirow[t]{2}{*}{ Surveys } & \multirow[t]{2}{*}{ Interviews } & \multirow[t]{2}{*}{ Delphi } & \multicolumn{2}{|c|}{ Minimum number of individuals participating in at least one stage } \\
\hline & & & & Brain tumour in vitro researchers & All participants \\
\hline Belgium & 1 & & 1 & 1 & 1 \\
\hline Brazil & 1 & & & 1 & 1 \\
\hline Germany & 4 & 1 & 2 & 4 & 5 \\
\hline Ireland & & 1 & 2 & 2 & 2 \\
\hline Italy & 1 & & 1 & 1 & 1 \\
\hline Luxembourg & 1 & & & 1 & 1 \\
\hline Netherlands & 3 & & & 3 & 3 \\
\hline Norway & 1 & & 2 & 2 & 2 \\
\hline Poland & & & 1 & 1 & 1 \\
\hline Slovenia & & & 1 & 1 & 1 \\
\hline Sweden & 1 & & & 1 & 1 \\
\hline United Kingdom & 5 & 11 & 7 & 7 & 15 \\
\hline United States & 16 & & 2 & 16 & 16 \\
\hline Total & 34 & 13 & 19 & 41 & 50 \\
\hline
\end{tabular}

may have discouraged participation. Other practical problems such as contact emails being filtered out by organisational email servers may also have had an impact. Additionally, the field of brain tumour research has, historically, been poorly funded (House of Commons Petitions Committee [HCPC], 2016) so that researchers are likely to be focused on core issues including grant income and job security and we anticipated that they may be less inclined to become involved in research that appears more peripheral to these aspects. Because of this, we chose a study design (as summarised in Figure 1) which drew on multiple data collection streams to inform the criteria for Delphi assessment (survey, interview, and documentary analysis). This was to ensure that the study design was resistant to risks associated with low response rates to survey or interviews. Nevertheless, more than 30 heads of laboratories/professors from 10 different countries did participate and, overall 40 in vitro brain tumour experts from 13 countries contributed to at least one stage of the process. This is a significant number in a relatively small field and these people represent experienced, senior authorities within the field. Furthermore, there was consistency in the criteria suggested in the survey, interview, and documents.

There was also consistency and a high level of agreement on the importance of each of the criteria proposed. The final outcome of the process reported in this paper is a set of 37 criteria which reached agreement as essential to consider when assessing the quality and/or human relevance of an in vitro study. The focus was on in vitro research in the brain tumour field but the majority of the criteria generated are generic and could be applied to other in vitro research areas, particularly those in the field of cancer.

The data collected included individual comments and feedback on each of the criteria and revealed areas where there are differences in opinions and practise which would benefit from further investigation. It will be necessary to further specify how each of the 'criteria' could best be applied in 
practise as, in some cases, this is implicit and/or contextspecific rather than explicit and/or universal. Thus, criteria refer to specific aspects of an in vitro study that should be assessed and not whether simply reporting this would constitute good practise or whether it is also necessary that the study meets a particular standard related to this aspect. For example, there was agreement on the importance of assessing 'cellular heterogeneity' but no specific standard of reporting or conduct is currently attached to this. The data collected will inform the next stage of the process which is to develop more detailed guidance on the application of the criteria in practise. This may require an in person meeting as is generally required for finalising guidance such as this (EQUATOR Network, 2020). Ultimately, the set of guidance generated could be disseminated and used by journals, grant awarding bodies, and peer reviewers. As has been proposed, producing and disseminating a set of agreed criteria for the assessment of in vitro studies will further support 'Meaningful contributions to the body of science' as they can evaluated and reproduced by other researchers in the field and are more accessible to those in related fields previously (Hartung et al., 2019).

\section{CONCLUSION}

The SAToRI-BTR project drew on a range of well-established methods for identification and appraisal of current practise standards. Through a rigorous, systematic process of expert review, the project has resulted in a set of preliminary criteria for use in assessment of quality and human relevance of in vitro brain tumour studies. Further development of these criteria, including potential strategies for adaptation and dissemination across different sub-fields of brain tumour research, will follow. While the focus of the study remains in the brain tumour field, the initial criteria identified and the methods through which they were developed remain applicable to a broader range of fields relating to in vitro research. It is therefore hoped that this investigation will prove useful empirically and methodologically, both within and beyond the specific focus of brain tumour studies.

\section{REFERENCES}

Al Saadi, T., Fala, S., Hassan Akl, H. A., El-badawy, M., Ghanem, M., Shamandy, B., et al. (2016). Tools For Methodological Quality And Risk Of Bias Assessment For In-Vitro Studies: A Systematic Review Protocol. Available online at: https://www.researchgate.net/institution/Vo_Truong_Toan_University/ department/Faculty_of_Medicine/stats (accessed February 1, 2020).

Altman, D. G., McShane, L. M., Sauerbrei, W., and Taube, S. E. (2012). Reporting recommendations for tumor marker prognostic studies (remark): explanation and elaboration. PLoS Med. 9:e1001216. doi: 10.1371/journal.pmed. 1001216

Aschner, M., Suñol, C., and Bal-Price, A. (eds) (2011). Cell Culture Techniques. Totowa, NJ: Humana Press.

ASNO (2017). The 14th Meeting of the Asian Society for Neuro-Oncology (Scientific Program). Available online at: http://asno2017.jp/data/program.pdf (accessed February 1, 2020).

\section{DATA AVAILABILITY STATEMENT}

The datasets presented in this article are not readily available because the small numbers of participants and specific nature of the responses mean that individuals may be identified. Anonymised data collated from the online survey are available on request from the authors. Requests to access the datasets should be directed to KP, karen.pilkington@port.ac.uk.

\section{ETHICS STATEMENT}

The studies involving human participants were reviewed and approved by University of Portsmouth Faculty of Science Ethics Committee, reference number SFEC 2018-073 (original application plus amendments). The patients/participants provided their written informed consent to participate in this study.

\section{AUTHOR CONTRIBUTIONS}

$\mathrm{KP}$ and GP conceptualised the study. $\mathrm{MB}, \mathrm{GP}, \mathrm{CH}$, and $\mathrm{KP}$ contributed to the design of the study. $\mathrm{MB}$ conducted the data collection. $\mathrm{MB}$ and $\mathrm{KP}$ carried out the analysis. MB and $\mathrm{KP}$ drafted the manuscript. All authors contributed to the final version of the manuscript.

\section{FUNDING}

This study was supported by a grant from Animal Free Research UK. The funding was unrestricted and the funders had no influence on the project design, conduct or reporting.

\section{ACKNOWLEDGMENTS}

The authors gratefully acknowledge the contribution of all participants in the study who completed the survey, participated in interviews or contributed to the Delphi process.

BNOS (2018). Abstracts from the BNOS 2017 Meeting June 21-23, 2017 John McIntyre Conference Centre. Edinburgh. Neuro. Oncol. 20, i1-i26. doi: 10.1093/ neuonc/nox 237

Boulkedid, R., Abdoul, H., Loustau, M., Sibony, O., and Alberti, C. (2011). Using and reporting the delphi method for selecting healthcare quality indicators: a systematic review. PLoS One 6:e20476. doi: 10.1371/journal.pone.0020476

Brazma, A., Hingamp, P., Quackenbush, J., Sherlock, G., Spellman, P., Stoeckert, C., et al. (2001). Minimum information about a microarray experiment (MIAME) - toward standards for microarray data. Nat. Genet. 29, 365-371. doi: 10.1038/ng1201-365

CAMARADES (2020). CAMARADES (Collaborative Approach to Meta-Analysis and Review of Animal Data from Experimental Studies). Available online at: http://www.dcn.ed.ac.uk/camarades/ (accessed February 1, 2020).

Carlsen, B., Glenton, C., and Pope, C. (2007). Thou shalt versus thou shalt not: a meta-synthesis of GPs' attitudes to clinical practice guidelines. Br. J. Gen. Pract. 57, 971-978. doi: 10.3399/096016407782604820 
CELL Press (2020). Structured Transparent Accessible Reporting (STAR). Available online at: https://www.cell.com/star-methods (accessed February 1, 2020).

Colquhoun, H. L., Squires, J. E., Kolehmainen, N., Fraser, C., and Grimshaw, J. M. (2017). Methods for designing interventions to change healthcare professionals' behaviour: a systematic review. Implement. Sci. 12, 1-11. doi: 10.1186/s13012017-0560-5

Corbin, J., and Strauss, A. (2014). Basics of Qualitative Research: Techniques and Procedures for Developing Grounded Theory. New York, NY: SAGE Publications.

Cycyota, C. S., and Harrison, D. A. (2006). What (Not) to expect when surveying executives: a meta-analysis of top manager response rates and techniques over time. Organ. Res. Methods 9, 133-160. doi: 10.1177/1094428105280770

Deng, K., Zhu, C., Ma, X., Jia, H., Wei, Z., Xiao, Y., et al. (2016). Rapid discrimination of malignant breast lesions from normal tissues utilizing raman spectroscopy system: a systematic review and meta-analysis of in vitro studies. PLoS One 11:e0159860. doi: 10.1371/journal.pone.0159860

EANO (2018). 13th meeting of the European association of neurooncology October 10-14, 2018 Stockholm. Sweden. Neuro. Oncol. 20, iii215-iii344. doi: 10.1093/neuonc/noy139

Elshafay, A., Omran, E., Abdelkhalek, M., El-Badry, M., Eisa, H., Fala, S., et al. (2019). Reporting quality in systematic reviews of in vitro studies: a systematic review. Curr. Med. Res. Opin. 35:1. doi: 10.1080/03007995.2019.1607270

EQUATOR Network (2020). Enhancing the QUAlity and Transparency Of Health Research. Available online at: https://www.equator-network.org (accessed March 1, 2020).

Eskes, C., Boström, A.-C., Bowe, G., Coecke, S., Hartung, T., Hendriks, G., et al. (2017). Good cell culture practices \& in vitro toxicology. Toxicol. Vitr. 45, 272-277. doi: 10.1016/j.tiv.2017.04.022

EU-NETVAL (2015). Summary Record: EU-NETVAL Meeting 26th-27th November 2015, Ispra, Italy. In (Ispra, Italy). Available online at: https://ec.europa.eu/ jrc/sites/jrcsh/files/eu-netval_meeting_2015_summary_record.pdf (accessed February 1, 2020).

EU-NETVAL (2016). Summary Record: EU-NETVAL Meeting 10-11th October 2016, Ispra, Italy. in (Ispra, Italy: European Commission). Available online at: https://ec.europa.eu/jrc/sites/jrcsh/files/summary_record_eu-netval_meeting 2016.pdf (accessed February 1, 2020).

EURL ECVAM (2014). EURL ECVAM Workshop "Inaugural Meeting of EUNETVAL Members" 26-27 June 2014. in (Ispra, Italy). Available online at: https: //ec.europa.eu/jrc/sites/jrcsh/files/eu-netval_june_2014mm-final.pdf (accessed February1, 2020).

FAIRSharing.org (2020). FAIRSharing.org. Available online at: https://fairsharing. org/ (accessed March 1, 2020).

Fan, W., and Yan, Z. (2010). Factors affecting response rates of the web survey: a systematic review. Comput. Human Behav. 26, 132-139. doi: 10.1016/j.chb. 2009.10.015

Fitch, K., Bernstein, S. J. J., Aguilar, M. D. D., Burnand, B., LaCalle, J. R. R., Lazaro, P., et al. (2001). The RAND / UCLA Appropriateness Method User's Manual. Available online at: https://www.rand.org/pubs/monograph_reports/MR1269. html (accessed February 1, 2020).

Gardner, J., and Webster, A. (2016). The social management of biomedical novelty: facilitating translation in regenerative medicine. Soc. Sci. Med. 156, 90-97. doi: 10.1016/j.socscimed.2016.03.025

Geraghty, R. J., Capes-Davis, A., Davis, J. M., Downward, J., Freshney, R. I., Knezevic, I., et al. (2014). Guidelines for the use of cell lines in biomedical research. Br. J. Cancer 111, 1021-1046. doi: 10.1038/bjc.2014.166

Hartung, T. (2018). Perspectives on in vitro to in vivo extrapolations. Appl. Vitr. Toxicol. 4, 305-316. doi: 10.1089/aivt.2016.0026

Hartung, T., Balls, M., Bardouille, C., Blanck, O., Coecke, S., Gstraunthaler, G., et al. (2002). Good cell culture practice: ECVAM good cell culture practice task force report 1. ATLA Altern. to Lab. Anim. 30, 407-414. doi: 10.1177/ 026119290203000404

Hartung, T., De Vries, R., Hoffmann, S., Hogberg, H. T., Smirnova, L., Tsaioun, K., et al. (2019). Toward good in vitro reporting standards. ALTEX 36, 3-17. doi: 10.14573/altex.1812191

House of Commons Petitions Committee [HCPC] (2016). Funding For Research Into Brain Tumours. First Report of Session 2015-16. HC 554. London: The Stationery Office Limited.
Higgins, J., and Green, S. (eds) (2011). Cochrane Handbook for systematic reviews of interventions. Version 5.1.0. The Cochrane Collaboration. Available online at: https://handbook-5-1.cochrane.org/ (accesssed February 1, 2020).

Higgins, J. P. T., Altman, D. G., Gøtzsche, P. C., Jüni, P., Moher, D., Oxman, A. D., et al. (2011). The Cochrane Collaboration's tool for assessing risk of bias in randomised trials. BMJ 343:928. doi: 10.1136/bmj.d5928

Hsu Chia, C., and Brian, A. S. (2007). The delphi technique: making sense of consensus. Pract. Assess. Res. Eval. 12:27071. doi: 10.1576/toag.7.2.120.27071

ICLAC (2019a). Cell Line Checklist for Manuscripts and Grant Applications. Available online at: https://iclac.org/wp-content/uploads/ICLAC_Cell-LineChecklist_v2_1.docx (accessed February 1, 2020).

ICLAC (2019b). International Cell Line Authentication Committee - Definitions. Available online at: https://iclac.org/resources/definitions/ (accessed February 1, 2020).

Kenall, A., Edmunds, S., Goodman, L., Bal, L., Flintoft, L., Shanahan, D. R., et al. (2015). Better reporting for better research: a checklist for reproducibility. Genome Biol. 16, 15-17. doi: 10.1186/s13059-015-0710-5

Kilkenny, C., Browne, W. J., Cuthill, I. C., Emerson, M., and Altman, D. G. (2010). Improving bioscience research reporting: the ARRIVE guidelines for reporting animal research. PLoS Biol. 8:e1000412. doi: 10.1371/journal.pbio.1000412

Klimisch, H.-J., Andreae, M., and Tillmann, U. (1997). A systematic approach for evaluating the quality of experimental toxicological and ecotoxicological data. Regul. Toxicol. Pharmacol. 25, 1-5. doi: 10.1006/rtph.1996.1076

Krippendorff, K. (2018). Content Analysis: An Introduction to Its Methodology. New York, NY: SAGE Publications.

Laaksonen, M., Sorsa, T., and Salo, T. (2010). Emdogain in carcinogenesis: a systematic review of in vitro studies. J. Oral Sci. 52, 1-11. doi: 10.2334/josnusd. 52.1

Lynch, H. N., Goodman, J. E., Tabony, J. A., and Rhomberg, L. R. (2016). Systematic comparison of study quality criteria. Regul. Toxicol. Pharmacol. 76, 187-198. doi: 10.1016/j.yrtph.2015.12.017

McShane, L. M., Altman, D. G., Sauerbrei, W., Taube, S. E., Gion, M., Clark, G. M., et al. (2005). REporting recommendations for tumour MARKer prognostic studies (REMARK). Br. J. Cancer 93, 387-391. doi: 10.1038/sj.bjc.6602678

Moher, D. (1998). CONSORT: an evolving tool to help improve the quality of reports of randomized controlled trials. JAMA 279:1489. doi: 10.1001/jama.279. 18.1489

Moher, D., Liberati, A., Tetzlaff, J., and Altman, D. G. (2009). Preferred reporting items for systematic reviews and meta-analyses: the PRISMA statement. PLoS Med. 6:e1000097. doi: 10.1371/journal.pmed.1000097

NC3Rs (2020). The National Centre for the Replacement, Refinement and Reduction of Animals in Research (NC3Rs). The 3Rs. Available online at: https://www. nc3rs.org.uk/the-3rs (accessed February 1, 2020).

NIH (2017). Principles and Guidelines for Reporting Preclinical Research. Rigor Reprod. Available online at: https://www.nih.gov/research-training/rigorreproducibility/principles-guidelines-reporting-preclinical-research (accessed February 1, 2020).

NIH (2019). Nih Guidelines For Research Involving Recombinant Or Synthetic Nucleic Acid Molecules. Bethesda, MD: NIH.

NIH-OER (2015). Enhancing Reproducibility through Rigor and Transparency. Available online at: https://grants.nih.gov/grants/guide/notice-files/not-od-15103.html (accessed February 1, 2020).

Nuffield Council on BioEthics (2005). The Ethics of Research Involving Animals. Available online at: https://www.nuffieldbioethics.org/assets/pdfs/The-ethicsof-research-involving-animals-full-report.pdf (accessed February 1, 2020).

OECD (2004). The Application of the Principles of GLP to in vitro studies (Advisory Document of the Working Group on Good Laboratory Practice). Paris: OECD.

OECD (2005). Guidance Document On The Validation And International Acceptance Of New Or Updated Test Methods For Hazard Assessment. Paris: OECD.

OECD (2018). Guidance Document on Good In Vitro Method Practices. Paris: OECD.

Pamies, D., Bal-Price, A., Simeonov, A., Tagle, D., Allen, D., Gerhold, D., et al. (2017). Good cell culture practice for stem cells \& stem-cell-derived models. ALTEX 34, 95-132. doi: 10.14573/altex.1607121

QSR International (2018). NVIVO. Available online at: https://www. qsrinternational.com/nvivo/home (accessed February 1, 2020). 
Rooney, A. (2015). Extending a Risk-of-Bias Approach to Address In Vitro Studies. in National Toxicology Program Office of Health Assessment and Translation (USA: Environmental Protection Agency (EPA)). Available online at: https://ofmpub. epa.gov/eims/eimscomm.getfile?p_download_id=526750 (accessed February 1, 2020).

Schmidt, B. Z., Lehmann, M., Gutbier, S., Nembo, E., Noel, S., Smirnova, L., et al. (2017). In vitro acute and developmental neurotoxicity screening: an overview of cellular platforms and high-throughput technical possibilities. Arch. Toxicol. 91, 1-33. doi: 10.1007/s00204-016-1805-9

Schneider, K., Schwarz, M., Burkholder, I., Kopp-Schneider, A., Edler, L., KinsnerOvaskainen, A., et al. (2009). “ToxRTool”, a new tool to assess the reliability of toxicological data. Toxicol. Lett. 189, 138-144. doi: 10.1016/j.toxlet.2009. 05.013

SNO (2017a). Abstracts from the 22nd annual scientific meeting and education day of the society for neuro-oncology. Neuro-Oncology 19(Suppl._6), vi1-vi314. doi: 10.1093/neuonc/nox168

SNO (2017b). Society for Neuro-oncology 22nd Annual Meeting and Education Day. SNO. Available online at: https://www.soc-neuro-onc.org/UploadedFiles/ 2017_SNO_Program_final.pdf (accessed February 1, 2020).

S-SANOC (2017). Report of The First Sub-Saharan Africa Neuro-Oncology Collaborative (S-SANOC) Planning Meeting. S-SANOC. Available online at: http://www.snossa.org/wp-content/uploads/2018/04/IBTA_SSANOC-Report_ FINAL-20Mar2018.pdf (accessed February 1, 2020).

Taylor, C. F., Field, D., Sansone, S. A., Aerts, J., Apweiler, R., Ashburner, M., et al. (2008). Promoting coherent minimum reporting guidelines for biological and biomedical investigations: the MIBBI project. Nat. Biotechnol. 26, 889-896. doi: $10.1038 /$ nbt. 1411

UKCCCR (2000). UKCCCR guidelines for the use of cell lines in cancer research. Br. J. Cancer 82, 1495-1509. doi: 10.1054/bjoc.1999.1169

WFNOS (2017a). 5th Quadrennial Meeting of the World Federation of NeuroOncology Societies. Seoul: WFNOS.

WFNOS (2017b). World Federation of Neuro-oncology Societies (WFNOS) 2017 Meeting Final Programme. Available online at: https://www.eano.eu/fileadmin/ content/WFNOS_2017/2017_WFNOS_Final_Programme_for_print.pdf (accessed February 1, 2020).

Xiao, Z., Li, C., Shan, J., Luo, L., Feng, L., Lu, J., et al. (2011). Mechanisms of renal cell apoptosis induced by cyclosporine a: a systematic review of in vitro studies. Am. J. Nephrol. 33, 558-566. doi: 10.1159/000328584

Conflict of Interest: The authors declare that the research was conducted in the absence of any commercial or financial relationships that could be construed as a potential conflict of interest.

Copyright (c) 2020 Bracher, Pilkington, Hanemann and Pilkington. This is an openaccess article distributed under the terms of the Creative Commons Attribution License (CC BY). The use, distribution or reproduction in other forums is permitted, provided the original author(s) and the copyright owner(s) are credited and that the original publication in this journal is cited, in accordance with accepted academic practice. No use, distribution or reproduction is permitted which does not comply with these terms. 